\title{
Voice Over Internet Protocol (VOIP) Pada Jaringan Nirkabel Berbasis Raspberry Pi
}

\author{
Rini Handayani ${ }^{{ }^{1}}$, Abdul Aziz $^{2}$, Anang Sularsa ${ }^{3}$ \\ 1,2,3 Universitas Telkom Bandung \\ rini.handayani@tass.telkomuniversity.ac.id ${ }^{*}$
}

\begin{abstract}
Abstrak
Voice Over Internet Protocol (VolP) merupakan satu teknologi telekomunikasi yang mampu melewatkan layanan komunikasi dalam jaringan Internet Protocol sehingga memungkinkan antar pengguna berkomunikasi suara dalam jaringan IP. Kelebihan dari VoIP ini mampu melakukan efisiensi bandwith dan biaya pengelolaan dengan memanfaatkan Raspberry Pi sebagai server VolP. Dalam penelitian ini, VolP dibangun pada Sistem Operasi Linux dengan aplikasi Asterisk dan RasPBX yang diintegrasikan pada Raspberry Pi dengan menggunakan jaringan nirkabel lokal sebagai media transmisi. Sistem ini diujikan dengan menggunakan dua tipe client, yaitu PC dan smartphone dengan mengukur QoS dengan rata-rata delay $0.4463 \mathrm{~ms}$, rata-rata throughput $16.36 \mathrm{KBps}$, rata-rata packet loss $0.889 \%$ dan jitter $1.102 \mathrm{~ms}$.
\end{abstract}

Kata kunci: Asterisk, VoIP Server, RasPBX, Raspberry Pi, Quality of service (QoS)

\begin{abstract}
Voice Over Internet Protocol (VolP) is a telecommunications technology that is able to deliver communication services in Internet Protocol networks that enable voice communication between clients in an IP network. The advantages of VoIP are able to perform bandwidth efficiency and cost management by utilizing the Raspberry Pi as a VolP server. In this study, VoIP is built on the Linux Operating System with Asterisk and RasPBX applications that are integrated in the Raspberry Pi using a local wireless network as the transmission media. This system was tested using two types of client, such as PCs and smartphones to measure QoS with an average delay $0.4463 \mathrm{~ms}, 16.36 \mathrm{KBps}$ average throughput, $0.889 \%$ average packet loss and jitter $1.102 \mathrm{~ms}$.
\end{abstract}

Keywords: Asterisk, VolP Server, RasPBX, Raspberry Pi, Quality of service (QoS)

\section{Pendahuluan}

Komunikasi merupakan hal utama yang mendukung seluruh kegiatan yang ada dalam setiap kehidupan manusia. Begitu juga pada kegiatan Praktikum yang berlangsung di Fakultas IImu Terapan khususnya pada lantai 4 dan lantai 1 Fakultas IImu Terapan. Sebagai sarana bertukar informasi antara laboran, dosen, dan asisten praktikum yang berada di lantai 4 dan koordinator laboran di lantai 1 maka komunikasi pun harus dengan mudah dilaksanakan. Keterbatasan dalam melakukan komunikasi yang diakibatkan oleh beberapa faktor kecil dapat menghambat kinerja proses belajar mengajar dan praktikum yang ada di lantai 4 dan lantai 1 Fakultas IImu Terapan. Kerapnya interaksi antar laboran, asisten praktikum, dan dosen pengampu mata kuliah saat berlangsungnya kegiatan praktikum sering sekali menghabiskan resource seperti kredit pulsa dan waktu koordinasi.

Sebagai solusi alternatif dari permasalahan tersebut adalah dengan menerapkan teknologi komunikasi pada wilayah lokal dengan biaya rendah [1], yang dalam penggunaannya tidak memerlukan kredit pulsa untuk komunikasi, yaitu dengan membangun VolP. Voice over Internet Protocol (juga disebut VoIP, IP telephony, internet telephony atau digital phone) adalah teknologi yang memungkinkan percakapan suara jarak jauh melalui media internet. Data suara diubah menjadi kode digital dan dialirkan melalui jaringan yang mengirimkan paket-paket data [2].

Untuk membangun VoIP dibutuhkan server yang selalu standby selama waktu kegiatan perkuliahan dan praktikum. Selain itu, server yang digunakan juga diharapkan tidak mahal dan

Handayani, R. (2017). Voice Over Internet Protocol (VOIP) Pada Jaringan Nirkabel Berbasis Raspberry Pi. KINETIK, 2(2), 82-88. doi:http://dx.doi.org/10.22219/kinetik.v2i2.146

Makalah dikirim 25 Januari 2017; Revisi 22 Maret 2017; Diterima 6 April 2017 
tidak membutuhkan daya listrik tinggi. Oleh karena itu, Raspberry Pi digunakan sebagai server VolP pada penelitian ini [3].

Sistem komunikasi VolP pada penelitian ini dibangun pada Raspberry Pi [4] [5] sebagai server dengan menggunakan sistem operasi RasPBX dan client yang beragam, seperti smartphone Android, iPhone, dan laptop pada jaringan lokal [6]. RasPBX merupakan proyek khusus yang menggabungkan Asterisk dan FreePBX yang difokuskan untuk Raspberry Pi. RasPBX ini menggunakan sistem operasi dasar Raspbian, Asterisk versi 11 dan FreePBX 12. Antarmuka pada client menggunakan beragam aplikasi softphone, seperti 3CXPhone. Interkoneksi client-server ini menggunakan wireless network sehingga memudahkan skalabilitas jaringan [7].

\section{Metode Penelitian}

Dalam membangun sistem ini dimulai dengan menentukan spesifikasi kebutuhan perangkat yang akan digunakan baik perangkat keras maupun perangkat lunak. Jaringan intranet yang telah dibangun pada Fakultas IImu Terapan dapat dimanfaatkan dalam pembangunan ini [8] [9]. Hal yang perlu diperhatikan dalam membangun sistem ini adalah dengan memperhatikan kebutuhan bandwidth pada masing-masing client. Pembagian Bandwidth pada jaringan VolP dibagi berdasarkan banyaknya jumlah client (dalam hal ini jumlah laboran yang disesuaikan dengan jumlah ruangan yang ada pada Lantai 4 Fakultas IImu Terapan Universitas Telkom).

Tabel 1. Kebutuhan Bandwidth

\begin{tabular}{cccc}
\hline Deskripsi & Lokasi & $\begin{array}{c}\text { Bandwidth } \\
\text { Maksimum }\end{array}$ & $\begin{array}{c}\text { Jumlah } \\
\text { Client }\end{array}$ \\
\hline VolP WLAN & Lt. 4 & $1 \mathrm{Mbps}$ & 12 \\
\hline
\end{tabular}

Pada jaringan tersebut diberi batasan sebesar 1 MBps dengan jumlah client yang dapat mengakses sebanyak 12 client sesuai kebutuhan laboran dan dosen. Layanan yang diberikan hanya berupa layanan voice dengan codec yang digunakan u-law, a-law, dan H.276.

Perangkat yang digunakan pada penelitian ini antara lain Raspberry Pi dengan sistem operasi RasPBX dan aplikasi FreePBX sebagai server VolP, WirelessRouter sebagai access point, beberapa smartphone dengan aplikasi 3Cx phone, CSIP simple, dan Zoiper sebagai client, dan laptop/PC yang diperuntukkan juga sebagai client. Adapun langkah-langkah pengerjaan yang dilakukan antara lain sebagai berikut:

1. Konfigurasi Server - Raspberry Pi, meliputi sistem operasi, aplikasi PBX, dan jaringan

2. Konfigurasi Wireless Router, meliputi gateway, IP Address

3. Konfigurasi Client, meliputi PC dan smartphone

4. Pengukuran QoS, meliputi delay, throughput, packet loss, jitter

Dari penentuan kebutuhan penelitian maka dibangun sebuah topologi yang dapat dijadikan solusi dari analisis kebutuhan tersebut. Pemilihan topologi ini dikarenakan kebutuhan client yang dianggap sesuai.

Perancangan Topologi pada Gambar 1 disesuaikan dengan kebutuhan yang dijabarkan pada Tabel 1. Pada Gambar 2 digambarkan bagaimana gambaran lalu lintas komunikasi dari sistem yang dibangun. Sistem ini dibangun terdiri dari 1 buah Raspberry Pi 1 buah Router sebagai Access point, 1 admin dan beberapa client. Raspberry Pi berfungsi sebagai server VoIP yang menjadi alternatif server VoIP pada umumnya yang digunakan pada komputer biasa atau komputer server. Router berfungsi sebagai access point yang membagi atau menyebarkan IP dari server ke seluruh client. Admin berfungsi sebagai client control management.

\section{Hasil Penelitian dan Pembahasan}

Setelah dibangunnya server dan client selanjutnya dilakukan pengujian sistem dengan skenario sebagai berikut:

1. Fungsionalitas komunikasi antar client.

2. Quality of service (QoS) pada layanan VoIP.

3. Pengaturan batasan bandwidth yang dapat dilalui tidak melebihi dari $1 \mathrm{Mbps}$.

4. Kinerja prosesor Raspberry Pi meliputi CPU usage dan suhu. 


\subsection{Fungsionalitas Komunikasi Antar Client}

Sebelum melakukan panggilan, administrator perlu menambahkan client pada server VoIP dengan mendaftarkannya pada client SIP kemudian client juga mengonfigurasi dirinya dengan memberikan nama dan caller ID pada aplikasi softphone yang telah tertanam. Setelah client terdaftar pada server VoIP, maka panggilan antar client dapat berlangsung.

\subsection{Quality of service pada Layanan VolP}

Dari pengujian yang dilakukan pada dua belas client secara simultan didapat nilai ratarata pada jitter $1.102 \mathrm{~ms}$, delay $0.4463 \mathrm{~ms}$, throughput $16.36 \mathrm{KBps}$, dan packet loss $0.889 \%$. Data pengukuran Quality of Service (QoS) ini terinci pada Tabel 2.

\subsection{Pengaturan Bandwidth}

Melalui RasPBX, administrator dapat melakukan pengaturan bandwidth maksimum yang dapat dilalui oleh masing-masing client. Pada jaringan yang dibangun pada penelitian ini, bandwidth maksimum yang dapat dilalui adalah tidak melebihi dari 1 Mbps. Untuk mengukur besar bandwidth yang digunakan oleh masing-masing client dapat terpantau pada TCPDump dengan rinci pada Tabel 3.

\subsection{Kinerja prosesor Raspberry Pi}

Pengukuran Tabel 4 terhadap prosesor Raspberry Pi juga dilakukan untuk menguji ketahanan, sehingga Raspberry Pi dapat dijadikan sebagai server.

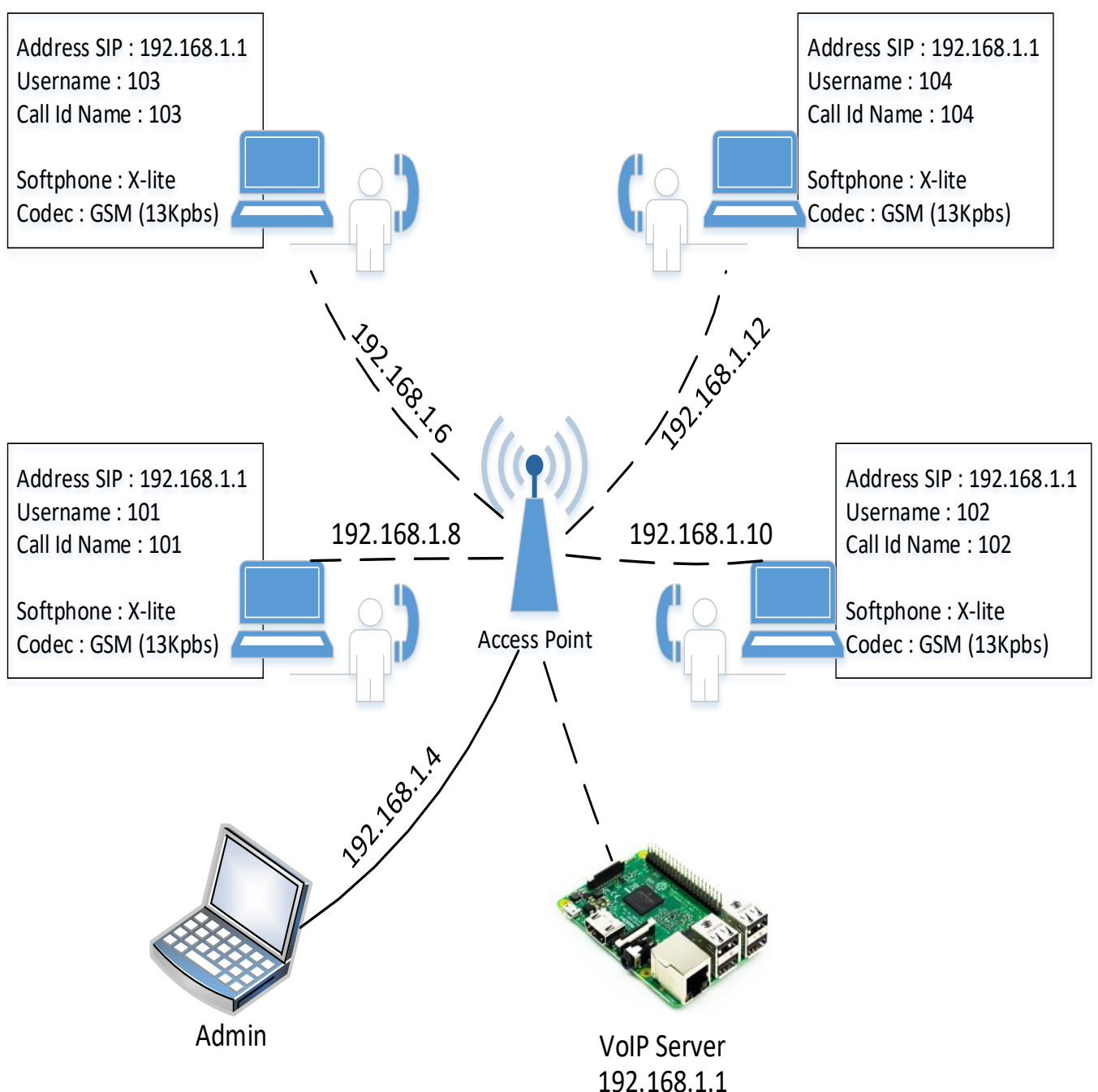

Gambar 1. Topologi Perancangan Sistem 


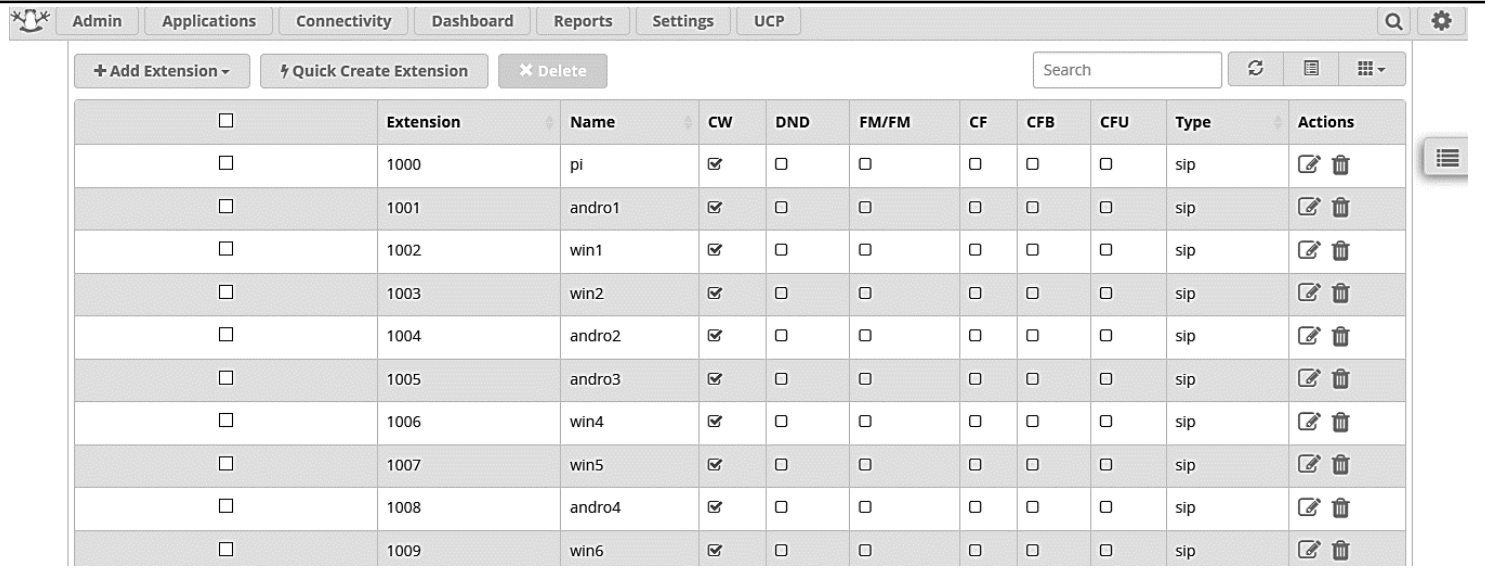

(a)

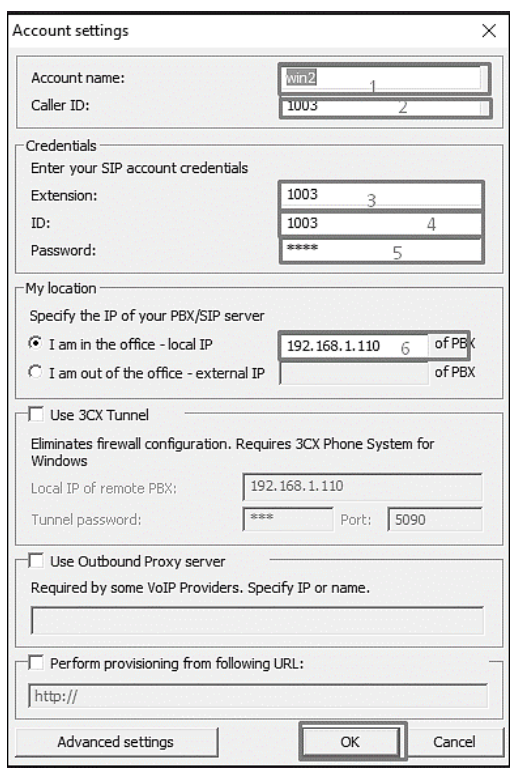

(b)

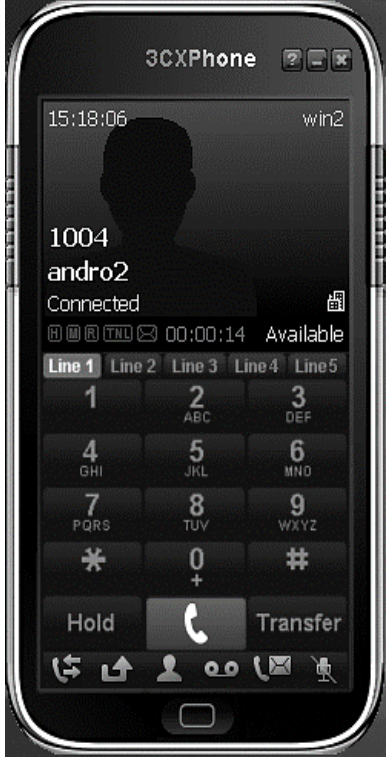

(c)

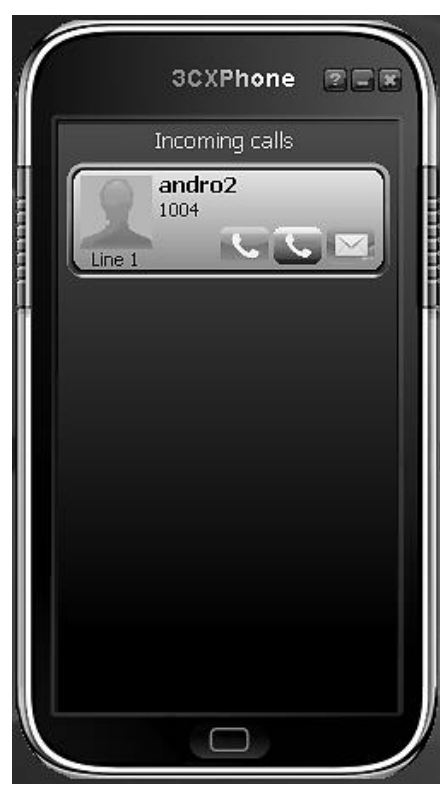

Gambar 2. (a) Penambahan Client pada Server; (b) Pendaftaran Client pada Softphone Client; (c) Pengujian Interkoneksi Antar Client

Tabel 2. Pengukuran Quality of Service

\begin{tabular}{cccccc}
\hline No & IP Client & Jitter $(\mathrm{ms})$ & Delay $(\mathrm{ms})$ & $\begin{array}{c}\text { Throughput } \\
\text { (KBps) }\end{array}$ & $\begin{array}{c}\text { Packet Loss } \\
(\%)\end{array}$ \\
\hline 1 & 192.168 .1 .13 & 0.342 & 0.0321 & $2.6 \mathrm{kbps}$ & 0.1 \\
2 & 192.168 .1 .45 & 1.426 & 0.0371 & $11 \mathrm{kbps}$ & 0.0 \\
3 & 192.168 .1 .50 & 0.068 & 0.0055 & $28 \mathrm{kbps}$ & 0.0 \\
4 & 192.168 .1 .16 & 1.286 & 0.5003 & $26 \mathrm{kbps}$ & 0.0 \\
5 & 192.168 .1 .23 & 1.062 & 0.6098 & $21 \mathrm{kbps}$ & 0.1 \\
6 & 192.168 .1 .28 & 1.244 & 0.6609 & $18 \mathrm{kbps}$ & 2.07 \\
7 & 192.168 .1 .17 & 0.406 & 0.0782 & $6.7 \mathrm{kbps}$ & 0.81 \\
8 & 192.168 .1 .42 & 2.114 & 0.0035 & $19 \mathrm{kbps}$ & 0.2 \\
9 & 192.168 .1 .36 & 1.289 & 0.2456 & $13 \mathrm{kbps}$ & 0.1 \\
10 & 192.168 .1 .45 & 2.486 & 1.0086 & $20 \mathrm{kbps}$ & 0.59 \\
11 & 192.168 .1 .19 & 0.078 & 1.0862 & $11 \mathrm{kbps}$ & 1.7 \\
12 & 192.168 .1 .11 & 1.428 & 1.0886 & $20 \mathrm{kbps}$ & 5.0 \\
\hline
\end{tabular}




\begin{tabular}{ccc}
\multicolumn{3}{c}{ Tabel 3. Pengukuran Quality of Service } \\
\hline No & IP Client & $\begin{array}{c}\text { Bandwidth Terpakai } \\
\text { (KBps) }\end{array}$ \\
\hline 1 & 192.168 .1 .13 & 2.6 \\
2 & 192.168 .1 .45 & 11 \\
3 & 192.168 .1 .50 & 28 \\
4 & 192.168 .1 .16 & 26 \\
5 & 192.168 .1 .23 & 21 \\
6 & 192.168 .1 .28 & 18 \\
7 & 192.168 .1 .17 & 6.7 \\
8 & 192.168 .1 .42 & 19 \\
9 & 192.168 .1 .36 & 13 \\
10 & 192.168 .1 .45 & 20 \\
11 & 192.168 .1 .19 & 11 \\
12 & 192.168 .1 .11 & 20 \\
\hline \multicolumn{3}{c}{ Jumlah Bandwith } \\
Terpakai & 196.3 \\
\hline \multicolumn{3}{c}{ Rata-rata Bandwith } \\
Terpakai \\
\hline
\end{tabular}

Tabel 4. Pengukuran Suhu dan CPU Usage Pada Raspberry Pi

\begin{tabular}{ccccc}
\hline No & Pukul & Suhu $\left({ }^{\circ} \mathrm{C}\right)$ & CPU Usage $(\%)$ & Jumlah Client \\
\hline 1 & 17.00 & 27.1 & 29 & 4 \\
\hline 2 & 19.00 & 27.0 & 29 & 4 \\
\hline 3 & 21.00 & 27.0 & 30 & 4 \\
\hline 4 & 23.00 & 29.6 & 36 & 7 \\
\hline 5 & 01.00 & 29.5 & 34 & 6 \\
\hline 6 & 03.00 & 29.1 & 34 & 6 \\
\hline 7 & 05.00 & 28.7 & 30 & 4 \\
\hline 8 & 07.00 & 28.6 & 30 & 4 \\
\hline 9 & 09.00 & 28.5 & 30 & 4 \\
\hline 10 & 11.00 & 32.8 & 48 & 10 \\
\hline 11 & 13.00 & 33.3 & 59 & 12 \\
\hline 12 & 15.00 & 31.5 & 36 & 8 \\
\hline
\end{tabular}

\section{Kesimpulan}

Berdasarkan dari proses selama implementasi dan pengujian yang telah dilakukan terhadap sistem, dapat disimpulkan bahwa pembangunan server VolP berbasis Raspberry Pi berhasil dilakukan dan berjalan dengan baik, baik di PC ataupun di smartphone dengan menggunakan softphone 3CX phone untuk PC dan CSIP simple untuk smartphone. Hal ini ditunjukkan dengan kinerja prosesor Raspberry $\mathrm{Pi}$ saat sistem berjalan dan juga pengukuran QoS ketika komunikasi berlangsung antar client yang memenuhi standar QoS ITU-T G114 [10].

\section{Referensi}

[1] L. Laurenz And E. Putro, "Perancangan Dan Pembangunan Sistem Voice Over Internet Protocol," Teknik dan IImu Komputer., Vol. 2, No. 1, Pp. 221-231, 2012.

[2] O. Purbo And A. Raharja, "Voip Cookbook: Building Your Own Telecommunication Infrastructure," Internet Society Innovtion Fund, 2010.

[3] R. Dawood, S. Qiana, And S. Muchallil, "Kelayakan Raspberry Pi Sebagai Web Server: Perbandingan Kinerja Nginx, Apache, Dan Lighttpd Pada Platform Raspberry Pi," Jurnal Rekayasa Elektrika, Vol. 11, No. 1, Pp. 25-29, 2014.

[4] S. F. Rakhman E, Candrasyah F, Raspberry Pi, Mikrokontroler Mungil Yang Serba Bisa. Yogyakarta: Penerbit Andi, 2015.

[5] D. N. R. Ahmad Sven Heddin Timoryansyah, Hafidudin, "Implementasi Voip Server Dengan Menggunakan Mini Pc," E-Proceeding Applied Science., Vol. 1, No. 3, Pp. 1-8, 2015. 
[6] R. R. I. Irwan Andaltria, Sudjadi Sudjadi, "Layanan Call Conference Menggunakan Asterisk Di Dalam Jaringan Lokal," Transient, Vol. 2, No. 1, Pp. 202-208, 2013.

[7] Nurindriyan Bintang Pamungkas, Simulasi Bandwidth Management Dengan Metode Queue Tree Dan Pemanfaatan Scripting Pada Router Os Mikrotik, Tugas Akhir. Universitas Telkom Bandung, 2013.

[8] P. K. Sudiarta And G. Sukadarmika, "Penerapan Teknologi Voip Untuk Mengoptimalkan Penggunaan Jaringan Intranet Kampus Universitas Udayana," Jurnal Teknologi Elektro, Vol. 8, No. 2, Pp. 62-70, 2009.

[9] L. Yulianto, A. Rochim, And T. Andromeda, "Perancangan Dan Implementasi Perangkat Lunak Telephone IP Pada Jaringan Komputer Lokal," Transmisi, Vol. 13, No. 4, Pp. 127-134, 2011.

[10] International Telecommunication Union. ITU-T Rec G114, Transmission Systems and Media, Digital Systems and Networks. Geneva: ITU-T Press, 2003. 